\title{
Valores hematológicos de tartarugas marinhas Chelonia mydas (Linaeus, 1758) juvenis selvagens do Arquipélago de Fernando de Noronha, Pernambuco, Brasil
}

Marcelo Renan de Deus SANTOS ${ }^{1}$

Larissa Santos FERREIRA ${ }^{2}$

Cecília BATISTOTE ${ }^{3}$

Alice GROSSMAN ${ }^{3}$

Cláudio BELLINI ${ }^{3}$

Correspondência para:

Marcelo Renan de Deus Santos,

R. Fortunato Ramos, 123.

Sta. Lúcia, Vitória, ES. CEP: 29055-290,

mrenansantos@gmail.com;

mrenan@uvv.br

Recebido para publicação: 06/01/2006 Aprovado para publicação: 24/09/2009

1 - Curso de Medicina Veterinária do Centro Universitário Vila Velha, Vila Velha-ES

2 - Instituto de Ensino, Pesquisa e Preservação Ambiental Marcos Daniel, Local-ES

3 - Fundação Pró-TAMAR, Vitória-ES

\section{Resumo}

Foram determinados os valores hematológicos de referência para 60 tartarugas marinhas Chelonia mydas juvenis selvagens aparentemente saudáveis do Arquipélago de Fernando de Noronha, Pernambuco, Brasil nos meses de julho a setembro de 2003. Os resultados obtidos foram: Hematócrito 21,4 a 36,6 \%; Hemácias 0,244 a 0,554 ×10\%/ $\mathrm{l}$; Hemoglobina 5,9 a 14,0 g/dl; Volume Corpuscular Médio 500,4 a 986,1 fl; Hemoglobina Corpuscular Média 144,0 a 367,1 pg; Concentração de Hemoglobina Corpuscular Média 23,7 a 45,1 g/dl; Leucócitos 1178,8 a 8259,6 / $\mu$ l; Monócitos 15,4 a 1494,3 / $\mu$ l; Linfócitos 221,1 a 1924,8 / $\mu$ l; Heterófilos 621,5 a 4317,8 / $\mu$ l; Eosinófilos 96,1 a

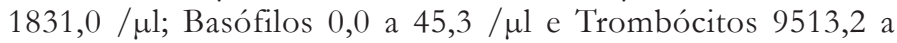
$36316,5 / \mu \mathrm{l}$. A comparação dos resultados obtidos com os dados da literatura reforça a necessidade do estabelecimento de valores hematológicos específicos para aglomerações em diferentes condições geográficas, climáticas, faixas de tamanho e diferentes metodologias. Devido a estas influências estes valores não devem ser extrapolados para outras aglomerações e devem ser usados com critério para avaliação clínica de indivíduos sob outras condições.

\section{Introdução}

Determinar o estado fisiológico de uma população ameaçada de extinção como a das tartarugas marinhas ${ }^{1}$, é de extrema importância para desenvolver planos de conservação apropriados, principalmente no que diz respeito à atenção à saúde dos animais e avaliações da saúde populacional ${ }^{2}$. Não há relatos publicados de estabelecimento de valores de referência hematológicos para tartarugas marinhas selvagens no Brasil e no mundo existem poucos trabalhos com Chelonia mydas (C. mydas), tartarugas-verdes selvagens, sendo a extrapolação destes para as populações de cativeiro e vice-versa inapropriada, pois pode haver diferenças significativas como resultado de dietas artificiais ou condições estressantes que estas últimas sofrem. ${ }^{3}$
Palavras-chave: Tartaruga verde. Chelonia mydas. Hematologia. Valores de referência. Sangue.
Em se tratando de répteis, outro fator limitante para utilização destes dados é que os valores sanguíneos variam muito e sofrem influência de fatores como idade, tamanho, sexo, saúde, dieta, estação do ano, habitat, o que dificulta o estabelecimento de valores de referência e comparações entre indivíduos e populações. ${ }^{4,5,6}$ Outra dificuldade é a variação de métodos de coleta, manipulação e processamento das amostras que existe entre os estudos, sendo um empecilho para comparação entre eles. ${ }^{7}$

Os programas de conservação de tartarugas marinhas têm se voltado cada vez mais para o monitoramento da saúde das populações, devido ao risco imposto pela fibropapilomatose cutânea, enfermidade mais importante como ameaça à conservação das tartarugas marinhas. Tratase de uma neoplasia de etiologia 
provavelmente viral que se manifesta na forma de tumores pedunculares de 0,5 a 30 $\mathrm{cm}$ de diâmetro e tumores internos que afetam o metabolismo. ${ }^{8} \mathrm{~A}$ doença é debilitante na medida em que interfere na capacidade visual, de locomoção e de alimentação do animal, de acordo com o grau e local de acometimento ${ }^{9}$, gerando quadros de imunossupressão, emaciação e perda da capacidade de fuga de predadores. Em alguns casos a doença é fatal. Os parâmetros bioquímicos e hematológicos podem ser afetados em função da condição crônica debilitante da doença e da presença de tumores internos ${ }^{10,11}$. Fatores como parasitas, temperatura, poluentes ${ }^{12} \mathrm{e}$ biotoxinas podem estar relacionados com o desenvolvimento da doença, bem como com o comportamento desta no hospedeiro ${ }^{13}$. Normalmente os programas de monitoramento se dão em longo prazo, e levantam dados biométricos, geográficos, físico-químicos, anátomo-patológicos, sorológicos, parasitológicos, toxicológicos, bioquímicos e hematológicos de animais encalhados, capturados ou consumidos. ${ }^{14}$

Neste contexto, a determinação de valores hematológicos tem sido utilizada como ferramenta de avaliação da saúde dos animais. ${ }^{10,15}$ Estudos hematológicos comparativos de animais doentes e sadios podem gerar informações importantes para o manejo e conservação das espécies, porém, as informações geradas terão aplicabilidade limitada se não for estabelecido o padrão do que é normal para determinada população ${ }^{8}$ bem como a fisiologia e as alterações patológicas e como estas refletemse nos parâmetros laboratoriais. É necessário que cada laboratório procure estabelecer a faixa de referência pertinente às metodologias por ele utilizadas ${ }^{16}$ e também para as diferentes populações ${ }^{10,17,18}$.

Este trabalho teve como objetivo determinar os valores para eritrograma, leucograma e contagem de trombócitos, de tartarugas marinhas juvenis selvagens da espécie Chelonia mydas, aparentemente saudáveis do arquipélago de Fernando de Noronha, Pernambuco, Brasil.

\section{Material e Método}

Foram coletadas amostras sanguíneas de 60 tartarugas marinhas juvenis selvagens da espécie C. mydas no Parque Nacional Marinho de Fernando de Noronha, estado de Pernambuco, Brasil, localizado a 03 49', OS de latitude e $032^{\circ} 24^{\prime} \mathrm{W}$ de longitude, no período de julho a setembro de 2003. A área é protegida por lei e é considerada de baixo impacto antrópico e livre de poluição. As capturas foram realizadas por mergulho livre entre as praias do Porto de Santo Antônio e Sancho (Mar de Dentro), e Baía do Sueste (Mar de Fora) (Figura 1).

Após a contenção física e desinfecção do local de punção com álcool iodado, foram coletados $5 \mathrm{ml}$ de sangue do Seio Venoso Cervical ${ }^{19} \mathrm{com}$ seringas e agulhas 25 x $0,7 \mathrm{~mm}$ ou $40 \times 1,2 \mathrm{~mm}$ descartáveis dependendo do tamanho do animal, e depositados em tubo contendo $50 \mu \mathrm{l}$ (5.000 UI/ml) de heparina sódica ${ }^{7}$. Foram preparados três esfregaços sanguíneos para cada amostra com sangue, sem anticoagulante, diretamente da seringa. As amostras foram analisadas no mesmo dia da colheita em um laboratório montado para este fim. Após a colheita de amostras, foi feita a biometria dos animais (comprimento e largura curvilínea de carapaça) e a marcação com marcas de inconel (National Band and Tag Co., USA, modelo 681) nas nadadeiras dianteiras, conforme metodologia padrão adotada pelo Projeto TAMAR/IBAMA ${ }^{20}$.

A determinação do hematócrito (Htc) foi feita por centrifugação do sangue em tubos capilares a $11.000 \mathrm{RPM}$ por 5 minutos em centrífuga para hematócrito (Eureka 1, BIO ENG ${ }^{\circledR}$ ) e leitura em escala própria ${ }^{18}$. As contagens totais de eritrócitos (He) e leucócitos (L) foram feitas em câmara de Neubauer com uma diluição de 1:50 em solução de Natt e Herrick ${ }^{18}$. A dosagem de hemoglobina $(\mathrm{Hb})$ foi feita pelo método de cianometahemoglobina reagindo $10 \mu \mathrm{l}$ de sangue total com $5 \mathrm{ml}$ do reagente de cor (de acordo com as orientações do fabricante - Labtest ${ }^{\circledR}$ ) em cubetas cilíndricas de $10 \mathrm{~mm}$ 


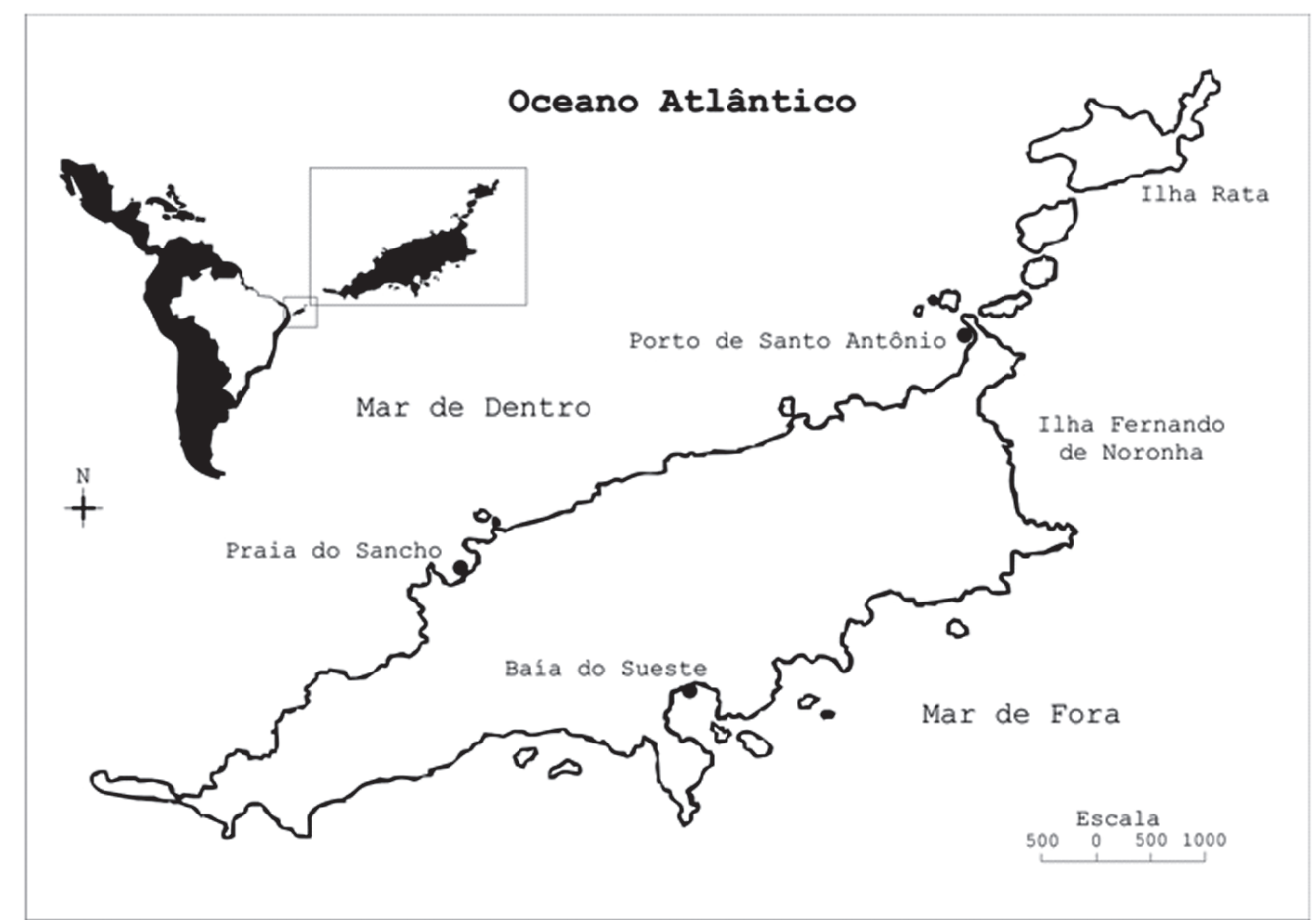

Figura 1 - Localização da área de estudo com a indicação dos locais de captura das tartarugas, Arquipélago de Fernando de Noronha, Pernambuco, Brasil (03 ${ }^{\circ} 49^{\prime} \mathrm{S}$ de latitude e $032^{\circ} 24^{\prime} \mathrm{W}$ de longitude)

em espectrofotômetro $\left(432 \mathrm{C}\right.$, Femto $\left.^{\circledR}\right)$, com filtro de $540 \mathrm{~nm}$ e comparado com um padrão de $10 \mathrm{mg} / \mathrm{dl}$. Os valores do volume corpuscular médio (VCM), da hemoglobina corpuscular média (HCM) e da concentração de hemoglobina corpuscular média (CHCM), foram calculados a partir dos valores obtidos para Htc, $\mathrm{Hb}$ e $\mathrm{He}^{18}$. A avaliação da morfologia dos eritrócitos e contagem diferencial de leucócitos foi realizada a partir dos esfregaços sanguíneos corados pelo método panótico rápido $\left(\right.$ Laborclin $\left.^{\mathbb{B}}\right)$ tipo Romanowsky. A caracterização da morfologia celular foi feita seguindo a classificação de Work et al. ${ }^{21}$ A contagem de trombócitos foi realizada a partir da contagem proporcional destes em 500 hemácias no esfregaço sanguíneo.

A estatística descritiva dos valores obtidos e a análise quanto à simetria de distribuição de freqüência dos dados foram feitas no programa MS EXCEL ${ }^{\circledR}$. As faixas de valores de referência para os parâmetros com distribuição assimétrica foram compreendidas entre os $2,5^{\circ}$ e $97,5^{\circ}$ percentis e para valores com distribuição simétrica dentro de um intervalo entre a média $\pm 1,96$ Desvio Padrão (DP ${ }^{17}$. A avaliação da correlação do tamanho com o Htc foi feita por correlação de Pearson usando o software SPSS 10.0.

\section{Resultados e Discussão}

Foram capturados 60 animais medindo entre 29,1 a 59,9 $(55,6 \pm 13,1) \mathrm{cm}$ de comprimento curvilíneo de carapaça, assim, todos os animais foram considerados juvenis ${ }^{22}$. Nesta fase do ciclo de vida não há dimorfismo sexual e, portanto não é possível determinar o sexo dos animais visualmente. Todos os animais capturados aparentavam estarem clinicamente sadios. Os valores de média e desvio padrão (média $\pm \mathrm{DP}$ ) e a faixa de valores de referência obtidos no eritrograma das 60 amostras de C. mydas juvenis capturadas estão descritos na tabela 1. Não foi possível realizar a contagem diferencial de um indivíduo, assim, os valores 
Tabela 1 - Valores de referência para eritrograma $(n=60)$ e leucograma $(n=59)$ de Chelonia mydas, juvenis, selvagens aparentemente sadias do Arquipélago de Fernando de Noronha, - Pernambuco, Brasil - 2003

\begin{tabular}{lcc}
\hline Parâmetros & Média $\pm \mathrm{DP}$ & Intervalo de Referência \\
\hline Hematócrito $(\%)$ & $29,0 \pm 3,9$ & 21,4 a 36,6 \\
Hemácias $\left(\mathrm{x} 10^{6 / \mu \mathrm{l})}\right.$ & $0,399 \pm 0,079$ & 0,244 a 0,554 \\
Hemoglobina $(\mathrm{g} / \mathrm{dl})$ & $10,0 \pm 2,0$ & 5,9 a 14,0 \\
$\mathrm{VCM}(\mathrm{fl})$ & $743,2 \pm 123,9$ & 500,4 a 986,1 \\
$\mathrm{HCM}(\mathrm{pg})$ & $255,6 \pm 56,9$ & 144,0 a 367,1 \\
$\mathrm{CHCM}(\mathrm{g} / \mathrm{dl})$ & $34,4 \pm 5,4$ & 23,7 a 45,1 \\
Leucócitos $(/ \mu \mathrm{l})$ & $3553,5 \pm 1920,5$ & 1178,8 a 8259,6 \\
Monócitos $(/ \mu 1)$ & $333,6 \pm 501,3$ & 15,4 a 1494,3 \\
Linfócitos $(/ \mu \mathrm{l})$ & $712,8 \pm 431,4$ & 221,1 a 1924,8 \\
Heterófilos $(/ \mu \mathrm{l})$ & $1926,7 \pm 912,0$ & 621,5 a 4317,8 \\
Eosinófilos $(/ \mu)$ & $575,9 \pm 440,0$ & 96,1 a 1831,0 \\
Basófilos $(/ \mu)$ & $4,8 \pm 16,5$ & 0,0 a 45,3 \\
Trombócitos $(/ \mu \mathrm{l})$ & $20535,3 \pm 9651,7$ & 9513,2 a 36316,5 \\
\hline
\end{tabular}

de leucograma e contagem de trombócitos foram obtidos de 59 indivíduos. Os valores obtidos para o eritrograma foram apresentaram distribuição normal, portanto a faixa de referência compreende os valores entre a média $\pm 1,96$ vezes o desvio padrão. Os valores de leucograma e trombócitos foram analisados não parametricamente, assim, a faixa de referência compreendeu os valores entre 2,5 e 97,5 percentis. Com relação à classificação morfológica das células, foram encontrados sete tipos celulares: eritrócitos, linfócitos, monócitos, heterófilos, eosinófilos, basófilos e trombócitos. A ordem de predominância numérica dos leucócitos foi a seguinte: heterófilos, linfócitos, eosinófilos, monócitos e basófilos.

A colheita de amostras para avaliação hematológica pode interferir nos resultados obtidos. Especialmente em quelônios, a proximidade dos vasos sanguíneos e linfáticos pode promover contaminação da amostra com linfa ${ }^{6}$. O local de eleição para colheita em tartarugas marinhas é o seio venoso cervical ou veia jugular externa, pois apresentam vantagens como facilidade de acesso e fácil contenção dos animais, não havendo necessidade do uso de anestesia local ou geral. A técnica não provoca injúrias ao animal e assim, este pode ser liberado logo após a colheita, não sendo necessário acompanhamento de sua recuperação ${ }^{19}$. Apesar de Wood e Ebanks ${ }^{5}$ relatarem não existir diferença associada ao método de coleta para valores de hematócrito e hemoglobina, um estudo específico sobre possíveis locais para venopunção em tartaruga terrestre (Gopherus agassizii), revelou significativa diminuição $(\mathrm{P} \leq 0,05)$ dos valores de hematócrito, contagem total de eritrócitos, leucócitos e concentração de hemoglobina, além de variações nos valores bioquímicos de amostras obtidas do seio venoso cervical ou veia jugular externa comparadas com amostras obtidas da veia jugular ${ }^{6}$. Este fato foi atribuído a hemodiluição das amostras pela contaminação por linfa. Devido a esta possibilidade, foi tomado o devido cuidado de observar as amostras quanto à contaminação por linfa, pois a presença de fluidos contaminantes é facilmente perceptível no início do procedimento de venopunção.

O anticoagulante usado foi a heparina sódica. O EDTA (ácido etilenodiaminotetracético) é normalmente usado para mamíferos. Atua quelando o 
cálcio e outros eletrólitos, mas provoca hemólise extensa em répteis, especialmente em quelônios. ${ }^{7,23}$ Apesar disso, Wood e Ebanks $^{5}$ relatam o uso de EDTA e consideram este melhor que heparina ou citrato de sódio. A heparina de lítio é mais recomendável por interferir menos em dosagens bioquímicas, principalmente de sódio, mas até o momento não existem tubos com este anticoagulante comercialmente disponíveis no Brasil. Uma desvantagem da heparina é o prazo para o processamento das amostras relativamente curto (aproximadamente 6h), podendo haver agregação dos trombócitos e leucócitos ${ }^{16}$. Outro problema é a impossibilidade de realização de esfregaços sanguíneos com sangue heparinizado, pois a coloração fica esverdeada, impedindo a diferenciação das células, como foi verificado na prática. As características morfológicas de eritrócitos neste estudo são semelhantes às de outros répteis, inclusive quanto à presença de organelas em degeneração encontradas em eritrócitos de tartaruga terrestre do deserto ${ }^{6}$. Estas inclusões podem ser facilmente confundidas com hemoparasitas.

A média da contagem total de eritrócitos foi semelhante ao encontrado por Wood e Ebanks ${ }^{5}$ em tartarugas verdes com 30 meses de idade $(392.000 / \mu \mathrm{l})$, porém um pouco inferior ao encontrado por Aguirre et al. ${ }^{24}(480.000 / \mu \mathrm{l})$.

A concentração de hemoglobina apresentou valor maior que o encontrado por Aguirre et al. ${ }^{24}$ (média $8,54 \mathrm{~g} / \mathrm{dl}$ ) que trabalharam com tartarugas verdes de vida livre do Havaí. O valor encontrado neste estudo foi semelhante aos encontrados por Wood e Ebanks ${ }^{5}$ em C. mydas de diferentes idades: 30 meses de idade $(9,8 \pm 1,4 \mathrm{~g} / \mathrm{dl})$; 45 meses $(10,3 \pm 1,3 \mathrm{~g} / \mathrm{dl})$ e adultas ( $10,6 \pm 1,2 \mathrm{~g} / \mathrm{dl})$.

O resultado obtido para Htc ficou compreendido dentro da faixa de valores obtidos por Bolten e Bjorndal ${ }^{3}$, (26,442,0\%), que trabalharam com C. mydas clinicamente saudáveis no sul das Bahamas. Da mesma forma, ficaram dentro de alguns valores obtidos por Wood e Ebanks ${ }^{5}$, que trabalharam com tartarugas verdes de 6 meses $(24,0-51,0 \%)$ e 18 meses $(18,0-53,0 \%)$. De acordo com estes últimos autores e com Frair ${ }^{25} \mathrm{o}$ hematócrito aumenta com a idade. Como não é possível estimar a idade pela biometria, não foi possível a análise dos valores obtidos em função da idade, mas analisando o hematócrito em função do tamanho, não foi possível estabelecer qualquer correlação para a faixa de tamanho da amostra estudada. É preciso destacar que os animais usados no estudo de Wood e Ebanks ${ }^{5}$, foram de cativeiro, que diferem daqueles de vida livre em vários fatores, influenciando conseqüentemente nos valores hematológicos ${ }^{25}$.

As médias dos valores dos índices hematimétricos obtidos foram menores que os encontrados por Aguirre et $\mathrm{al}^{24}$ (VCM 1214,36fl e HCM 317,12pg) com exceção do (CHCM 27,50\%). O cálculo dos índices hematimétricos CHCM e HCM em eritrócitos nucleados não leva em conta o volume do núcleo. Assim, é provável que os valores não reproduzam com exatidão a realidade das proporções hemoglobínicas, sendo, portanto um tema importante para outros estudos.

A média obtida para contagem total de leucócitos foi bastante diferente das encontradas por Aguirre et al. ${ }^{24}(9.340,0 / \mu \mathrm{l})$,

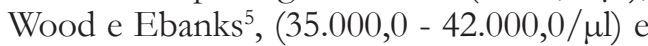
Work e Balazs ${ }^{26}(11.890 \pm 800 / \mu \mathrm{l})$. Estas diferenças podem se dar em função de fatores inerentes a metodologia de contagem ou a fatores diversos que afetem a cinética leucocitária como estresse, alimentação, geográficos entre outros. Outros métodos de contagem, como o uso do Unopette System $5877^{\circledR} \mathrm{BD}$, podem gerar valores diferentes ${ }^{21}$. A contagem na câmara de Neubauer tem um erro intrínseco de até $20 \%$, podendo afetar sensivelmente os resultados ${ }^{27}$.

Os valores encontrados nas contagens diferenciais de leucócitos mostraram-se em desacordo com a literatura consultada, em parte em função das diferenças na contagem total de leucócitos. Além disso, sabe-se que 
em tartarugas, fatores extrínsecos (estação do ano, habitat, método de coleta sanguínea, tipo de análise do sangue) e fatores intrínsecos (sexo, estresse, idade, estado de saúde) complicam o estabelecimento de valores de referência sanguíneos e a comparação destes entre indivíduos e populações diferentes ${ }^{6}$. Outra possibilidade para essas diferenças foi a dificuldade de diferenciação, em alguns casos, entre linfócitos pequenos e trombócitos. A ordem de predominância das células foi a seguinte: heterófilos, linfócitos, eosinófilos, monócitos e basófilos.
Work et al. ${ }^{21}$ encontraram uma ordem diferente (linfócitos, monócitos, heterófilos, eosinófilos e basófilos). Estas diferenças são devidas provavelmente à difícil diferenciação de algumas células na microscopia ótica. Estes autores se referem à dificuldade de diferenciação entre basófilos e trombócitos. A classificação morfológica dos leucócitos de acordo com Work et al. ${ }^{21}$ mostrou-se válida de acordo com a metodologia adotada (Figura 2). Vale ressaltar que estes autores foram os únicos que realizaram um estudo ultraestrutural das

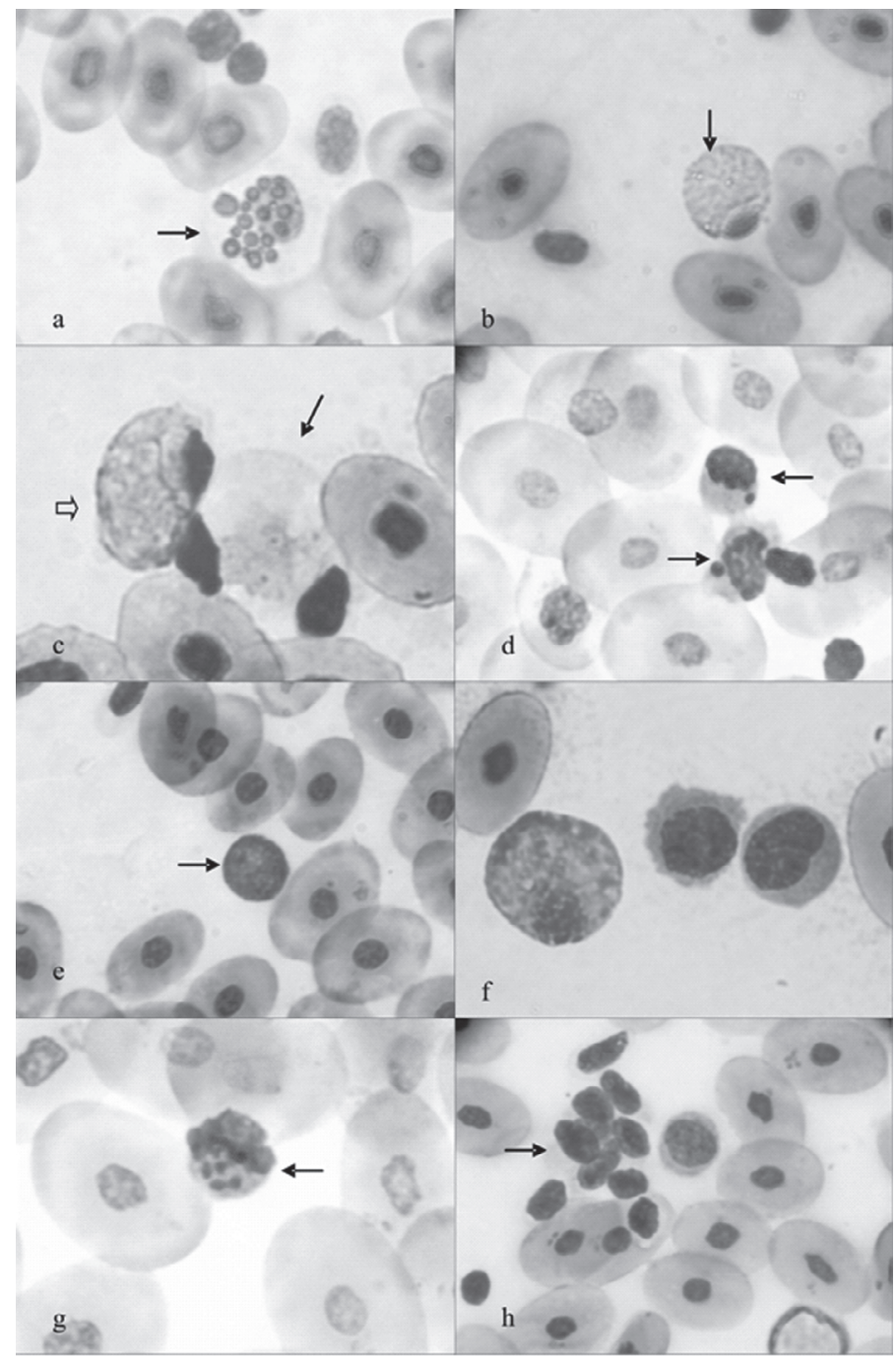

Figura 2 - Células sanguíneas de Chelonia mydas (coloração rápida de Romanowsky): a) Eosinófilo, b) heterófilo, c) heterófilo (seta larga) e eosinófilo com grânulos esparsos (seta estreita), d) 2 monócitos com grânulos basofílicos no citoplasma, e) linfócito, f) heterófilo (esquerda) e 2 monócitos (direita), g) monócito com 4 grânulos citoplasmáticos, h) aglomerado de trombócitos 
células, tendo mais subsídios para uma correta classificação. Anteriormente, Wood e Ebanks ${ }^{5}$ encontraram seis tipos celulares: eritrócito, linfócito, eosinófilo, basófilo, neutrófilo e trombócitos. Posteriormente, Aguirre et al. ${ }^{24}$ também trabalhando com C. mydas no Havaí, classificaram as células como eritrócitos, heterófilos, neutrófilos, linfócitos, eosinófilos e basófilos. A diferença entre estas classificações está basicamente na presença ou não do neutrófilo. Saint Girons ${ }^{28}$, identificou neutrófilos em répteis, o que contradiz com Sypek e Borysenko ${ }^{29}$, que não os identificaram. Segundo Work et al. ${ }^{21}$, neutrófilos são caracterizados por possuírem um núcleo segmentado e não haver grânulos citoplasmáticos distinguíveis, por isso não foram identificados na circulação de C. mydas, sendo considerados raros em répteis, mas têm sido vistos em tuataras (Sphenodon punctatus). A única exceção quanto a uma característica morfológica foi a presença de grânulos basofílicos no citoplasma de monócitos de algumas amostras, não relatada por outros autores.

Wood e Ebanks ${ }^{5}$ relatam um percentual de 2 a 64\% de trombócitos em relação ao total de leucócitos em C. mydas juvenis, sendo, portanto evidente a grande variação entre indivíduos, como também foi verificado neste trabalho.

\section{Conclusões}

Os valores hematológicos encontrados variaram em relação a outros autores, mesmo trabalhando com a mesma espécie e mesma faixa de tamanho, porém com metodologias distintas. Isso reforça a necessidade do estabelecimento de valores de hematológicos específicos para cada população, levando-se em conta também as características como o tamanho dos animais e a metodologia utilizada. Apesar de ser possível realizar a contagem diferencial de leucócitos de C. mydas com colorações rápidas de rotina, para uma exata classificação, deve-se proceder a colorações citoquímicas específicas para os diferentes tipos celulares, visto que ocorrem grandes variações entre os valores de contagem diferencial de leucócitos entre diferentes autores. Os valores obtidos poderão ser utilizados em programas de monitoramento da saúde de tartarugas marinhas C. mydas juvenis no Arquipélago de Fernando de Noronha e em estudos comparativos com outras áreas desde que seja respeitada a metodologia de amostragem e de análise.

\section{Abstract}

The hematological reference ranges of sixty wild, apparently health, juvenile green sea turtles (Chelonia mydas) from the Fernando de Noronha Archipelago, Pernambuco State, Brazil, were determined between the months of July and September of 2003. The obtained results were: Packed cell volume 21,4-36,6\%; erythrocytes count 0,244$0,554 \times 10^{6} / \mu \mathrm{l}$; Hemoglobin 5,9-14,0 g/dl; Mean Corpuscular Volume 500,4-986,1 fl; Mean Corpuscular Hemoglobin 144,0-367,1 pg; Mean Corpuscular Hemoglobin Concentration 23,7-45,1 g/dl; Total

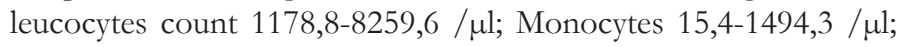
Lymphocytes 221,1-1924,8 / $\mu$ l; Heterophils $621,5-4317,8 / \mu$; Eosinophils 96,1-1831,0 / $\mu$; Basophils 0,0-45,3 / $\mu$; Trombocytes 9513,2-36316,5/ $\mu$ l. The comparison between the obtained results and literature data reinforce the need to establish hematological counts for specific agglomerations on different geographic and climate conditions, size classes, age, and methodologies. Because of these influences, the values should not be extrapolated to other C. mydas agglomerations and should be used carefully for the clinical evaluation of individuals under other conditions.
Key words: Green turtle. Chelonia mydas. Hematology. Reference values. Blood. 


\section{Referências}

1 IUCN/SSC. A Global strategy for the conservation of Marine Turtles. Gland, Switezerland: IUCN, 1995, 24 p. (IUCN/ /SSC Marine Turtle Specialist Group, Publication, 1).

2 ECKERT, K. L.; BJORNOAL, K. A.; ABREUGROBOIS, F. A.; DONNELY, M. (Ed.). Research and Management Techniques for the Conservation of Sea Turtles. Washington. DC: IUCN, 1999 p. 61-64. (IUCN/SSC Marine Turtle Specialist Group Publication, 4).

3 BOLTEN, A. B.; BJORNDAL, K. A. Blood profiles for a wild population of green turtles (Chelonia mydas) in the southern Bahamas: size-specific and sex-specific relationships. Journal of Wildlife Diseases, v. 28, n. 3, p. 407-413, 2002.

4 FRAIR, W. Sea turtle red blood cell parameters correlated with carapace lengths. Comparative Biochemistry and Phisiology, v. 56A, n. 4, p. 467-472, 1977.

5 WOOD, F. E.; EBANKS, G. Blood cytology and hematology of green sea turtle, Chelonia mydas. Herpetologica, v. 40, n. 3, p. 331-336, 1984.

6 GOTTDENKER, N. L.; JACOBSON, E. R. Effect of venipuncture sites on hematologic and clinical biochemical values in desert tortoises (Gopherus agassizii). American Journal of Veterinary Research, v. 56, n. 1, p. 19-21, 1995

7 BOLTEN, A. B.; JACOBSON, E. R.; BJORNDAL, K. A. Effects of anticoagulant and autoanalyzer on blood biochemical values of Loggerhead Sea Turtles (Caretta caretta). American Journal of Veterinary Research, v. 53, n. 12, p. 2224-2227, 1992.

8 AGUIRRE, A. A.; LUTZ, P. L. Marine turtles as sentinels of ecosystem health: is fibropapillomatosis an indicator? EcoHealth, v. 1, n. 3, p. 275-283, 2004.

9 GEORGE, R. H. Health problems and diseases of sea turtles. In: LUTZ, P. L.; MUSICK, J. A. (Ed.). The biology of sea turtles. Boca Raton: CRC Press, 1997. chap.14, p. $233-273$

10 AGUIRRE, A. A.; BALAZS, G. H. Blood biochemistry values of green turtles, Chelonia mydas, with and without fibropapillomatosis. Comparative Hematology International, v.10, n. 1, p. 132-137, 2000.

11 SWIMMER, J. Y. Biochemical responses to fibropapilloma and captivity in the green turtle. Journal of Wildlife Disease, v. 1, n. 36, p. 102-110, 2000.

12 HERBST, L. H.; KLEIN, P. A. Green turtle fibropapillomatosis: challenges to assessing the role of environmental cofactors. Environmental Health Perspectives, v. 103, n. 4, p. 27-30, 1995.

13 LANDSBERG, J. H.; BALAZS, G. H.; STEIDINGER,
K. A.; BADEN, D. G.; WORK, T. H.; RUSSEL, D. J. The potential role of natural tumor promoters in marine turtle fibropapillomatosis. Journal of Aquatic Animal Health, v. 11, p. 199-210, 1999.

14 AGUIRRE, A. A.; HARA, T. M. O.; SPRAKER, R T.; JESSUP, D. A. Monitoring the health and conservation of marine mammals, sea turtles, and their ecossystems. In: AGUIRRE, A. A.; OSTFELD, R. S.; TABOR, G. M.; HOUSE, C.; PEARL, M. C. (Ed.). Conservation medicine: ecological health in practice. New York: Oxford University Press, 2002. p. 79-94.

15 JACOBSON, E. R. Collecting and processing blood from sea turtles for hrmatologic and plasma biochemical determinations. In: REPORT OF THE SEA TURTLES HEALTH ASSESSMENT WORKSHOP, 1998, Charleston, USA, 1998, p. 24-31.

16 CAMPBELL, T. W. Clinical pathology. In: MADER, D. R Reptile medicine and surgery. Philadelphia: W. B. Saunders, 1996. p. 248-257.

17 FARVER, T. B. Concepts of normality in clinical biochemistry. In: KANEKO, J. J. Clinical biochemistry of domestic animals. 4. ed. San Diego: Academic Press, 1989. p. 1-20.

18 MADER, D. R. Normal hematology of reptiles. In FELDMAN, B. V.; ZINKL, J. G.; JAIN. N. C. (Ed.). Schalm's veterinary hematology. 5 . ed. Philadelphia: Lippincott Williams \& Willkins, 2000. p. 1126-1132.

19 OWENS, D. W.; RUIZ, G. J. New methods of obtaining blood and cerebrospinal fluid from marine turtle. Herpetologica, v. 36, n. 1, p. 17-20, 1980.

20 MARCOVALDI, M. A.; MARCOVALDI, G. G. Marine turtles of Brazil: the history and structure of Projeto TAMAR-IBAMA. Biological Conservation, $n$. 91, p. 35-41, 1999

21 WORK, T. M.; RASKIN R. E.; BALAZS, G. H.; WHITTAKER, S. D. Morphologic and cytochemical characteristics of blood cells from Hawaiian green turtle. American Journal of Veterinary Research, v. 59, n. 10, p. $1252-1257,1998$.

22 BALAZS, G. H.; MURAKAWA, S. K. K.; AGUIRRE, A. A. Manifestation of fibropapillomatosis and rates of growth of green turtles at Kaneohe Bay in the Hawaiian Islands. In: INTERNATIONAL SEA TURTLE SYMPOSIUM ON SEA TURTLE BIOLOGY AND CONSERVATION, 18., 1998, Mazatlan, México. Proceedings... Washington: Department of Commerce, (NOAA Technical Memorandum NMFS-SEFSC 436), 1998, p. 112-113.

23 KNOTKAVA, Z.; DOUBEK, J.; KNOTEK, Z.; HAIKOVA, P. Blood cell morphology and plasma biochemistry in Russian tortoises (Agrionemys harsfieldi). Acta Veterinaria Brunensis, v. 71, n. 2, p. 191-198, 2002

24 AGUIRRE, A. A.; BALAZS, G. H.; SPRAKER, T. R.; GROSS, T. S. Adrenal and hematological responses to stress in juvenile green turtles, Chelonia mydas, with 
and without fibropapilomas. Physiological Zoology, v. 68, n. 5, p. 831-854, 1995.

25 FRAIR, W. Turtles red blood cell packed volumes, sizes, and numbers. Herpetologica, v. 33, n. 2, p. $167-$ 190, 1977.

26 WORK, T. M.; BALAZS G. H. Relating tumor score to hematology in green turtles with fibropapillomatosis in Hawaii. Journal of Wildlife Diseases, v. 4, n. 35 p. 804-807, 1999.

27 COLES, E. H. Patologia clínica veterinária. São Paulo: Manole, 1989. 566 p.

28 SAINT GIRONS, M. C. Morphology of the circulating blood cells. In: GANS, C.; PARSON, T. C. Biology of the reptilia, San Diego: Academic Press Inc, 1970. v. 3, p. 73-91.

29 SYPEK, J.; BORYSENKO, M. Reptiles. In: ROWLEY A. F.; RATCLIFFE, N. A. (Ed.). Vertebrate blood cells. Cambridge, England: Cambridge University Press, 1988. p. $211-256$ 